\title{
Bronchodilator responsiveness or reversibility in asthma and COPD - a need for clarity
}

This article was published in the following Dove Press journal: International Journal of COPD

\author{
Igor Barjaktarevic' \\ Robert Kaner ${ }^{2,3}$ \\ Russell G Buhr ${ }^{1,4}$ \\ Christopher B Cooper ${ }^{1,5}$ \\ 'Division of Pulmonary and Critical \\ Care, David Geffen School of \\ Medicine at UCLA, Los Angeles, CA, \\ USA; ${ }^{2}$ Division of Pulmonary and \\ Critical Care, Weill Cornell Medicine, \\ NY, USA; ${ }^{3}$ Department of Genetic \\ Medicine, Weill Cornell Medicine, NY, \\ USA; ${ }^{4}$ Department of Health Policy \\ and Management, Fielding School of \\ Public Health at UCLA, Los Angeles, \\ CA, USA; ${ }^{5}$ Department of Physiology, \\ David Geffen School of Medicine at \\ UCLA, Los Angeles, CA, USA
}

Correspondence: Igor Barjaktarevic Division of Pulmonary and Critical Care, David Geffen School of Medicine at UCLA, 10833 Le Conte Avenue, CHS, 43233, Los Angeles, CA 90095, USA Email ibarjaktarevic@mednet.ucla.edu
Asthma and COPD present with multiple overlapping phenotypes, ${ }^{1-3}$ making a simplified diagnostic separation between the two disease states difficult. From a practical standpoint, the difficulty in differentiating between asthma and COPD has been a limitation and a foundation for criticism of large prospective trials. ${ }^{4}$ Multiple attempts to better define the population of patients with features of both diseases have been made, ${ }^{5,6}$ yet a common consensus about the best way to approach this problem is missing. Part of this problem relates to our reliance on oversimplified and relatively crude spirometric definitions of asthma and $\mathrm{COPD}^{7}$ and an incomplete understanding of how to interpret changes after bronchodilator administration. Imprecise definitions of the terms "bronchodilator responsiveness" and "reversibility" add to the confusion in the attempts to distinguish between COPD and asthma. Although the two terms are often used interchangeably in the published literature, ${ }^{8}$ and their difference may seem to be an issue of semantics, appropriately defining "bronchodilator responsiveness" and "reversibility" is essential for understanding the role of bronchodilator administration in the diagnostic workup of obstructive lung disease.

A diagnosis of COPD is currently defined by demonstrating the presence of persistent airflow obstruction postbronchodilator, which implies the lack of "reversibility" of the airflow obstruction following administration of the bronchodilator. Thus, based on their definitions, reversibility of airflow obstruction and COPD are mutually exclusive terms. ${ }^{7}$ In the narrowest sense, "reversibility" implies that the abnormality, in this case, airflow obstruction, returns to normal after bronchodilator administration. Clearly, this determination depends on the accepted definition of "abnormal," with Global Initiative for Chronic Obstructive Lung Diseases (GOLD) guidelines ${ }^{9}$ choosing a fixed ratio of $\mathrm{FEV}_{1} / \mathrm{FVC}<70 \%$, a subject that has generated much debate. ${ }^{10}$ Individuals with "reversible" obstruction are at higher risk of future development of COPD. ${ }^{11,12}$ The latest GOLD guidelines recommend the need to retest symptomatic subjects at risk of COPD with an $\mathrm{FEV}_{1} / \mathrm{FVC}$ ratio between $60 \%$ and $80 \%$ to account for variability of this measurement on repeated spirometry as "reversible" airflow obstruction on postbronchodilator spirometry may turn into a persistent airflow obstruction on follow-up testing. At the same time, the same subject with a reduced $\mathrm{FEV}_{1} / \mathrm{FVC}$ ratio of $<70 \%$ which normalizes after bronchodilator administration may have asthma. Nevertheless, "reversibility" is neither necessary nor sufficient for an asthma diagnosis. Spirometry in asthma may be completely normal between exacerbations, yet persistent, uncontrolled asthma may lead to "irreversible" airflow obstruction, where 
the degree of obstruction may be a function of the duration and severity of the disease..$^{13}$

By contrast, "bronchodilator responsiveness" can be defined in multiple ways, ${ }^{8}$ but it is inevitably based on measuring volume changes after bronchodilator administration. The American Thoracic Society (ATS) and European Respiratory Society (ERS) have adopted a definition of bronchodilator responsiveness as being an increase following bronchodilator of either $\mathrm{FEV}_{1}$ or $\mathrm{FVC}$ of $\geq 12 \%$ and $\geq 200$ $\mathrm{mL} .{ }^{14,15}$ Bronchodilator administration can also affect $\mathrm{FEV}_{1} /$ FVC ratio, but the presence or absence of a change from $<70 \%$ to $\geq 70 \%$ is not used to categorize the bronchodilator response into positive or negative. While "reversibility" is occasionally used as a criterion distinguishing between COPD and asthma-COPD overlap, often what is meant is "bronchodilator responsiveness." ",16 Such references may relate to the definition of the term "reversibility" in the seminal paper by Miller et al, ${ }^{14}$ on the standardization of spirometry. However, it is important to emphasize that lack of clarification of this term has a significant impact on our interpretation of multiple published studies. A majority of patients with COPD (52\%) demonstrate bronchodilator responsiveness, depending on its definition ( $\mathrm{FEV}_{1}$ vs FVC) and disease stage ${ }^{8}$ However, in the study by Prentice et al, ${ }^{17}$ among those with reversibility of airflow obstruction, only $28.1 \%$ had bronchodilator responsiveness. The repeatability of bronchodilator responsiveness is modest, with about $50 \%$ of patients with moderate to severe COPD changing their bronchodilator responsiveness status on a follow-up testing. ${ }^{18}$ In addition, oversimplified analysis of bronchodilator responsiveness as present or absent, based on defined ATS/ ERS criteria of $\geq 200 \mathrm{~mL}$ and $\geq 12 \%,{ }^{14}$ further diminishes the clinical usefulness of this spirometric measure in the evaluation of obstructive lung disease. In reality, bronchodilator responsiveness in COPD and asthma differ both quantitatively $^{8}$ and in the pattern that reflects pathophysiological processes. ${ }^{19}$ In COPD, especially in advanced disease, FVC responsiveness dominates, likely implicating the effect of bronchodilator on reduction of hyperinflation and air trapping, as opposed to the $\mathrm{FEV}_{1}$ responsiveness, which is usually seen as a marker of bronchoreactivity in larger airways.

What should we do then, in order to derive the best value from spirometry and to help us better understand airway pathophysiology? First, we need to recognize its limitations. Currently used metrics such as $\mathrm{FEV}_{1}$ and $\mathrm{FEV}_{1} / \mathrm{FVC}$ are not sufficiently sensitive to diagnose early or mild airway disease, ${ }^{20-22}$ and, while spirometric staging can be helpful with regard to prognosis, it is well accepted that spirometry alone does not fully characterize the many clinical manifestations of
COPD. ${ }^{9}$ What spirometry does reflect well is the physiology of respiratory system and the dynamic changes that occur over time. While the forced expiratory and inspiratory maneuver is an artificial concept and sometimes difficult for patients to perform, the maximal flow volume curves do provide a rich source of physiological data. Large observational studies, ${ }^{23,24}$ along with digital technology and machine learning, offer the opportunity to explore novel spirometric indices of airway disease and to compare these indices with early structural abnormalities (eg, parametric response mapping) noted on high-resolution computed tomography scans.

"Reversibility" and "bronchodilator responsiveness" are important spirometric features of a patient with obstructive airway disease, and they may provide useful information about the underlying pathobiology in a given patient. Nevertheless, distinguishing the two terms and better understanding of the limitations derived by their current and widely accepted definitions is of crucial importance as we try to use spirometry as a reference for building more sophisticated diagnostic models. ${ }^{6,25}$ In this regard, it is worth noting that uncertainty as to whether a patient has an overlap of asthma and COPD is unlikely to be resolved on the basis of spirometric criteria alone. We believe the term "reversibility" should be dropped from position statements and guidelines in the future. On the other hand, bronchodilator responsiveness, linked to evidence-based minimum clinically important differences, is a distinct clinical feature in comparison to reversibility and it occurs frequently in both asthma and COPD.

\section{Disclosure}

Dr Igor Barjaktarevic reports grants from AMGEN and GE Healthcare, and personal fees from Astra Zeneca, Grifols, CSL Behring, Boehringer Ingelheim, Verona Pharama and Fisher and Paykel Healthcare, outside the submitted work. Professor Christopher Cooper reports he is employed parttime by the GlaxoSmithKline as a global medical expert with responsibilities for external scientific engagement and internal medical education. The authors report no other conflicts of interest in this work.

\section{References}

1. Turner AM, Tamasi L, Schleich F, et al. Clinically relevant subgroups in COPD and asthma. Eur Respir Rev. 2015;24(136):283-298.

2. Bateman ED, Hurd SS, Barnes PJ, et al. Global strategy for asthma management and prevention: GINA executive summary. Eur Respir J. 2008;31(1):143-178.

3. Han MK, Agusti A, Calverley PM, et al. Chronic obstructive pulmonary disease phenotypes: the future of COPD. Am J Respir Crit Care Med.2010; 182(5):598-604.

4. Suissa S, Drazen JM. Making sense of triple inhaled therapy for COPD. N Engl J Med. 2018;378(18):1723-1724. 
5. Postma DS, Rabe KF. The asthma-COPD overlap syndrome. $N$ Engl $J$ Med. 2015;373(13):1241-1249.

6. Pascoe SJ, Wu W, Collison KA, Nelsen LM, Wurst KE, Lee LA. Use of clinical characteristics to predict spirometric classification of obstructive lung disease. Int J Chron Obstruct Pulmon Dis. 2018;13: 889-902.

7. Vogelmeier CF, Criner GJ, Martinez FJ, et al. Global strategy for the diagnosis, management, and prevention of chronic obstructive lung disease 2017 report: GOLD executive summary. Eur Respir J. 2017;49(3): 1700214 .

8. Hanania NA, Sharafkhaneh A, Celli B, et al. Acute bronchodilator responsiveness and health outcomes in COPD patients in the UPLIFT trial. Respir Res. 2011;12:6.

9. Vogelmeier CF, Criner GJ, Martinez FJ, et al. Global strategy for the diagnosis, management, and prevention of chronic obstructive lung disease 2017 report. GOLD executive summary. Am J Respir Crit Care Med. 2017;195(5):557-582.

10. van Dijk W, Tan W, Li P, et al. Clinical relevance of fixed ratio vs lower limit of normal of FEV1/FVC in COPD: patient-reported outcomes from the CanCOLD cohort. Ann Fam Med. 2015;13(1):41-48.

11. Vestbo J, Lange P. Can GOLD Stage 0 provide information of prognostic value in chronic obstructive pulmonary disease? Am J Respir Crit Care Med. 2002;166(3):329-332.

12. Aaron SD, Tan WC, Bourbeau J, et al. Diagnostic instability and reversals of chronic obstructive pulmonary disease diagnosis in individuals with mild to moderate airflow obstruction. Am J Respir Crit Care Med. 2017;196(3):306-314.

13. Ulrik CS, Backer V. Nonreversible airflow obstruction in life-long nonsmokers with moderate to severe asthma. Eur Respir J. 1999;14(4): 892-896.

14. Miller MR, Hankinson J, Brusasco V, et al. Standardisation of spirometry. Eur Respir J. 2005;26(2):319-338.
15. Pellegrino R, Viegi G, Brusasco V, et al. Interpretative strategies for lung function tests. Eur Respir J. 2005;26(5):948-968.

16. Hanania NA, Celli BR, Donohue JF, Martin UJ. Bronchodilator reversibility in COPD. Chest. 2011;140(4):1055-1063.

17. Prentice HA, Mannino DM, Caldwell GG, Bush HM. Significant bronchodilator responsiveness and "reversibility" in a population sample. COPD. 2010;7(5):323-330.

18. Calverley PM, Burge PS, Spencer S, Anderson JA, Jones PW. Bronchodilator reversibility testing in chronic obstructive pulmonary disease. Thorax. 2003;58(8):659-664.

19. Quanjer PH, Ruppel GL, Langhammer A, et al. Bronchodilator response in FVC is larger and more relevant than in $\mathrm{FEV}_{1}$ in severe airflow obstruction. Chest. 2017;151(5):1088-1098.

20. Capaldi DP, Zha N, Guo F, et al. Pulmonary imaging biomarkers of gas trapping and emphysema in COPD: (3)He MR imaging and CT parametric response maps. Radiology. 2016;279(2):597-608.

21. Woodruff PG, Barr RG, Bleecker E, et al. Clinical significance of symptoms in smokers with preserved pulmonary function. $N$ Engl J Med. 2016;374(19):1811-1821.

22. Harvey BG, Strulovici-Barel Y, Kaner RJ, et al. Progression to COPD in smokers with normal spirometry/low DLCO using different methods to determine normal levels. Eur Respir J. 2016;47(6):1888-1889.

23. Couper D, Lavange LM, Han M, et al. Design of the subpopulations and Intermediate outcomes in COPD study (SPIROMICS). Thorax 2014;69(5):492-495.

24. Regan EA, Hokanson JE, Murphy JR, et al. Genetic epidemiology of COPD (COPDGene) study design. COPD. 2010;7(1):32-43.

25. Dow L. Asthma versus chronic obstructive pulmonary disease exploring why "reversibility versus irreversibility" is no longer an appropriate approach. Clin Exp Allergy. 1999;29(6):739-743.

Dove Medical Press encourages responsible, free and frank academic debate. The content of the International Journal of Chronic Obstructive Pulmonary Disease 'Editorial' section does not necessarily represent the views of Dove Medical Press, its officers, agents, employees, related entities or the International Journal of Chronic Obstructive Pulmonary Disease editors. While all reasonable steps have been taken to confirm the content of each Editorial, Dove Medical Press accepts no liability in respect of the content of any Editorial, nor is it responsible for the content and accuracy of any Editorial.

International Journal of COPD

\section{Publish your work in this journal}

The International Journal of COPD is an international, peer-reviewed journal of therapeutics and pharmacology focusing on concise rapid reporting of clinical studies and reviews in COPD. Special focus is given to the pathophysiological processes underlying the disease, intervention programs, patient focused education, and self management protocols.

\section{Dovepress}

This journal is indexed on PubMed Central, MedLine and CAS. The manuscript management system is completely online and includes a very quick and fair peer-review system, which is all easy to use. Visit http://www.dovepress.com/testimonials.php to read real quotes from published authors. 